\title{
Poliomyelitis vaccination status among children in the Federal Territory of Kuala Lumpur 2007
}

\author{
P Senan, ${ }^{a}$ YK Loe, ${ }^{a} \mathrm{~K}$ Gurpreet, ${ }^{a} \mathrm{~A}$ Hayati, ${ }^{b} \mathrm{AM}$ Haliza, ${ }^{\circ} \mathrm{K}$ Novia, ${ }^{a} \mathrm{~N}$ Odhayakumar, ${ }^{a} \mathrm{~K}$ Fadzilah, ${ }^{a} \mathrm{CK}$ Chong, ${ }^{d} \mathrm{~S}$ Nirmal, ${ }^{a}$ \\ $S$ Balachandran ${ }^{d}$ and K Devan ${ }^{d}$ \\ Correspondence to Prathapa Senan (e-mail: prathapa.s@iku.moh.gov.my).
}

Introduction: Polio vaccination rates remain low in certain regions of Malaysia. The Federal Territory of Kuala Lumpur (FTKL) reported coverage of only $29.3 \%$ in 2005 and $61.2 \%$ in 2006, despite a Department of Health campaign to provide free three-round immunizations. The estimated numbers of live births used to calculate these rates may have artificially lowered the reported coverage percentages.

Methods: A descriptive, cross-sectional household survey was conducted throughout the FTKL in 2007 to assess the actual polio vaccination status of children aged 9 to 24 months. Minimum sample size was calculated and proportionately divided among the 11 FTKL parliamentary constituencies. Residential areas were then randomly selected for in-person interviews. We used the gathered information, verified by medical records, to calculate the actual vaccination coverage and to compare the rates determined by using estimated or registered live births for the region.

Results: Of the 1713 study participants, $98.3 \%$ had completed their polio vaccination schedule. Only 21 children had been partially vaccinated, and nine children were completely unvaccinated. FTKL residents had 20431 live births registered for 2006, as opposed to the official estimate of 28400 . When the registered value of live births was used to calculate vaccination coverage, the 2006 coverage increased (to $85.1 \%$ ).

Conclusion: Actual vaccination coverage in Kuala Lumpur was much higher than the estimated coverage previously reported, reflecting the expected success of the Department of Health immunization campaign. Estimated values of live births are insufficient to accurately determine vaccine status and should be avoided.

$\mathrm{P}$ oliomyelitis is a contagious viral disease, which mainly affects children below five years of age. In most cases, infection is self-limiting and manifests as fever and lethargy; however, in approximately $1 \%$ of cases, systemic infection leads to involvement of the central nervous system, resulting in severe paralysis and possibly even death. The highly communicable nature of poliovirus and existence of an effective vaccine led to the launch of the Global Polio Eradication Initiative by the World Health Organization (WHO), Rotary International, the US Centers for Disease Control and Prevention, and the United Nations Children's Fund in $1988 .{ }^{1}$ Widespread vaccination and education efforts, along with vigilant surveillance of the disease have resulted in near eradication of poliomyelitis worldwide.
Once a region achieves polio-free status (defined by the $\mathrm{WHO}$ as three years with zero indigenous poliovirus cases $)^{1}$ polio vaccination coverage is recommended to be maintained at more than $95 \%$ to ensure against cases of wild poliovirus infection and potential epidemic. Thus, it is critical for regional and national health departments to accurately monitor the performance of established vaccination systems (measured as the percentage of vaccination coverage in a particular population). Vaccination coverage is usually determined by mining reported data (the administrative method) or by actively gathering data from the target population (immunization coverage surveys).

Unfortunately, both of these methods can only provide estimates of coverage. The administrative method

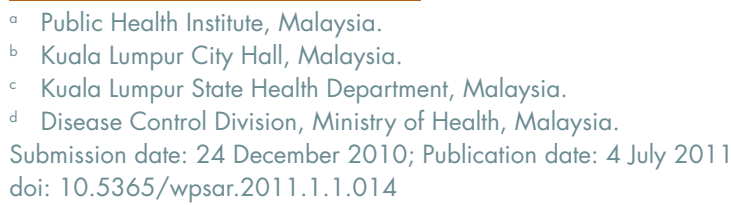


is particularly affected by lack of accurate population figures; for example, incomplete reporting can lead to underestimations, while over-representation of figures provided from vaccination programme units can lead to overestimations. Moreover, the administrative method relies on previously reported data which may be years old, making it incapable of timely identification of a potential risk. $^{2}$

According to $\mathrm{WHO}$, a minimum of three doses of polio vaccine, either by oral or injected route, are required for effective immunization. In Malaysia, three doses of trivalent oral polio vaccine are administered at 2, 3 and 5 months of age, followed by booster doses at 18 months and 6 years. The national polio vaccination coverage in the past two decades (1990 to 2009) is reported to have reached between $90 \%$ and $96 \%{ }^{3}$ Although these estimated figures appear high, they may in fact be overinflated, since the vaccination coverage data were principally obtained from government health care providers.

The Federal Territory of Kuala Lumpur (FTKL) represents the most highly populated urban region in Malaysia. Administrative-based estimates of polio vaccination coverage for this region have been as low as $29.3 \%$ (in 2005). ${ }^{4}$ This finding, however, was considered to be a result of private health care facilities failing to provide polio vaccination data to the State Health Department of Kuala Lumpur. Focused efforts to increase cooperation and feedback from the private sector led to the estimate of polio vaccination coverage increasing to $61.2 \%$ in 2006 . Statistical extrapolation of this estimate suggested that the actual coverage was above $85 \%{ }^{4}$

In this study, we aimed to determine the actual polio vaccination coverage in the FTKL for children born between June 2005 and August 2006 by using an in-person survey method. An additional objective was to determine if the denominator used in previous polio vaccine coverage estimates contributed to the low reported vaccine coverage.

\section{METHODS}

\section{Targeted geographic region}

According to the most recent census, the FTKL estimated population density is $6696 / \mathrm{km}^{2}{ }^{5}$ The entire metropolitan region is composed of 11 parliamentary constituencies of varying socioeconomic status. In 2008, 978 health care clinics (964 private and 14 government) and 17 hospitals (14 private and three government) were operating in the FTKL. ${ }^{4}$

\section{Study design}

A descriptive, cross-sectional household survey approach was employed for this study. Residential inperson interviews were conducted throughout the FTKL between 1 June and 15 July 2007. Study eligibility was extended to all children aged 9-24 months, whose birth dates were between 6 January 2005 and 31 August 2006, and who lived in the FTKL at the time of survey. This study was approved by the National Institutes of Health Malaysia, and written, informed consent was obtained from all parents or legal designates.

A minimum sample size of 1537 was calculated based on an estimated $80 \%$ coverage, with a $95 \%$ confidence interval and a desired precision of $2 \%$. The Sample Size Calculator for Prevalence Studies was used. $^{6}$ The minimal participant size was then apportioned among the 11 parliamentary constituencies, based upon the recorded population of each. Zoning maps were obtained from the Kuala Lumpur City Hall to define the residential areas within each constituency. The lottery method was used to assign order of interviewer visitation within each, until the target sample size for the parliamentary constituency was achieved.

\section{Data collection by the survey method}

Face-to-face interviews were conducted by trained interviewers using a pre-tested questionnaire. The information obtained from the interview was validated by cross-checking the child's vaccination records and birth certificate. Discrepancies were resolved by giving preference to the information from the vaccination records (for dates of vaccination) and the birth certificate (for calculating the age). Study participants were excluded if it was determined by recorded information that they were not within the stipulated age group. Incomplete questionnaires mandated a second visit to the household; if the questionnaires could not be completed, the data were excluded in its entirety.

For ethical reasons, those children identified during our survey who had not been vaccinated or had incomplete vaccination were vaccinated by the 
Table 1. Polio immunization sample size by parliamentary constituency

\begin{tabular}{lrrrrr}
\hline Parliamentary constituency & Population & Percentage & $\begin{array}{r}\text { Proportionate } \\
\text { sample }\end{array}$ & \multicolumn{2}{c}{ Actual sample (\%) } \\
\hline 1. Kepong & 8036 & 0.6 & 9 & 12 & $(0.7)$ \\
2. Batu & 66098 & 5.1 & 78 & 88 & $(5.1)$ \\
3. Wangsa Maju & 163870 & 12.7 & 195 & 217 & $(12.7)$ \\
4. Setiawangsa & 128671 & 10.0 & 154 & 169 & $(9.9)$ \\
5. Titiwangsa & 143266 & 11.1 & 171 & 190 & $(11.1)$ \\
6. Cheras & 115535 & 8.9 & 137 & 152 & $(8.9)$ \\
7. Bandar Tun Razak & 197724 & 15.3 & 235 & 263 & $(15.4)$ \\
8. Seputeh & 166570 & 12.9 & 198 & 220 & $(12.8)$ \\
9. Lembah Pantai & 136974 & 10.6 & 163 & 181 & $(10.5)$ \\
10. Segambut & 90646 & 7.0 & 108 & 120 & $(7.0)$ \\
11. Bukit Bintang & 75042 & 5.8 & 89 & 101 & $(5.9)$ \\
\hline \multicolumn{1}{c}{ Total } & 1292432 & 100.0 & 1537 & 1713 & $(100.0)$ \\
\hline
\end{tabular}

Source: Health Department, City Hall, Kuala Lumpur

health teams from the City Hall and the State Health Department.

\section{Data collection by the administrative method}

The total number of live births registered from 1 June 2005 to 30 November 2006 were obtained from the National Registration Department of FTKL. ${ }^{7}$

\section{Data Analysis}

Data were electronically recorded, housed, and analysed using Epi Info software (version 6; http://www.cdc.gov/ epiinfo).

Vaccination coverage (percentage) was calculated in this study as the number of participants who were fully vaccinated before survey divided by the total number of participants. In contrast, vaccination coverage (percentage) for the previous years that was reported by the FTKL State Health Department, National Statistics Department ${ }^{8}$ had been calculated as the total number of children vaccinated divided by the total number of live births.

\section{Ethics}

The study was approved by the ethics committee of the National Institutes of Health.

\section{RESULTS}

Nearly 30000 houses were visited in the 11 parliamentary constituencies and yielded a total of 1713 participants (see Table 1 ). The ethnic profile was principally composed of Malaysians (93.4\%). The male-to-female ratio was equal. Of the 1713 respondents, 1683 children (98.3\%; Cl: 97.5-99.2\%) had completed the three doses of poliomyelitis vaccination. Twenty-one children had received partial vaccination, and only nine children had received none of the vaccination doses. Over $95 \%$ of the children who had completed the vaccination regimen were Malaysians (Table 2).

More than three quarters $(78.8 \%)$ of the children had received their immunization in government facilities and $97.1 \%$ were able to provide vaccination records (Table 3). Correspondingly, the most common reason cited by the parents/guardian for not having completed the vaccination regimen was time constraints impeding transport of children to the site of vaccine administration. For the nine children who were unvaccinated, the reasons cited were related to distance of the clinic $(n=2)$, not knowing the whereabouts of the government clinics ( $n=6$ ), and not having time to take their children for vaccination $(n=1)$.

A total of 65534 live births were registered by the FTKL National Registration Department from 1 June 2005 to 30 November 2006; however, only $46.8 \%$ of the 25515 live births that occurred in 2005 had a residential address in the FTKL. Simple extrapolation of these numbers for the first five months of 2005 yielded an estimate of 43740 expected live births for the year, 20470 (46.8\%) of which were 


\begin{tabular}{|c|c|c|c|c|c|c|c|}
\hline \multirow{3}{*}{$\begin{array}{c}\text { Character } \\
\text { Participants }\end{array}$} & \multicolumn{7}{|c|}{ Vaccination status } \\
\hline & \multicolumn{2}{|c|}{$\begin{array}{l}\text { Completed vaccination } \\
\qquad(\%)\end{array}$} & \multicolumn{2}{|c|}{$\begin{array}{c}\text { Partial } \\
\text { vaccination (\%) }\end{array}$} & \multicolumn{2}{|c|}{ Not vaccinated (\%) } & \multirow{2}{*}{$\begin{array}{r}\text { Total } \\
1713\end{array}$} \\
\hline & 1683 & $(98.3)$ & 21 & (1.2) & 9 & $(0.5)$ & \\
\hline & \multicolumn{2}{|c|}{ (Cl: 97.5-99.2) } & & & & & \\
\hline \multicolumn{8}{|l|}{ Gender } \\
\hline Male & 839 & $(97.9)$ & 10 & $(1.2)$ & 8 & $(0.9)$ & 857 \\
\hline Female & 844 & $(98.6)$ & 11 & (1.3) & 1 & $(0.1)$ & 856 \\
\hline Total & 1683 & $(98.3)$ & 21 & $(1.2)$ & 9 & $(0.5)$ & 1713 \\
\hline \multicolumn{8}{|c|}{ Country of citizenship } \\
\hline Malaysia & 1600 & $(98.5)$ & 18 & (1.1) & 6 & $(0.4)$ & 1624 \\
\hline \multicolumn{8}{|c|}{ Ethic group } \\
\hline Malay & 1264 & $(98.5)$ & 14 & (1.1) & 5 & $(0.4)$ & 1283 \\
\hline Chinese & 186 & $(98.9)$ & 2 & (1.1) & 0 & & 188 \\
\hline Indian & 125 & $(97.7)$ & 2 & (1.5) & 1 & $(0.8)$ & 128 \\
\hline Other Bumis & 24 & $(100.0)$ & 0 & & 0 & & 24 \\
\hline Eurasian & 1 & $(100.0)$ & 0 & & 0 & & 1 \\
\hline Indonesia & 30 & $(88.2)$ & 3 & (8.8) & 1 & (2.9) & 34 \\
\hline Thailand & 0 & & 0 & & 1 & (100.0) & 1 \\
\hline Bangladesh & 1 & (100.0) & 0 & & 0 & & 1 \\
\hline Myanmar & 47 & $(97.9)$ & 0 & & 1 & (2.1) & 48 \\
\hline Pakistan & 3 & (100.0) & 0 & & 0 & & 3 \\
\hline Senegal & 1 & (100.0) & 0 & & 0 & & 1 \\
\hline Philippines & 1 & $(100.0)$ & 0 & & 0 & & 1 \\
\hline Total & 1683 & (98.3) & 21 & (1.2) & 9 & $(0.5)$ & 1713 \\
\hline
\end{tabular}

presumed to have a FTKL residential addresses. The 40019 registered live births for the 11 -month period of 2006 yielded an extrapolated value of 43656 live births for the entire year, of which 20431 (46.8\%) would be expected to have a FTKL residential address.

According to estimates obtained by the National Statistics Department, and used in the State Health Department's calculations of vaccine coverage, 27500 live births occurred in 2005 and 28400 in 2006 (Table 4). Of which, 20470 in 2005 and 20431 in
2006 were estimated to have residential address in FTKL. Actual data for the remaining registered live births indicated that the birth parents' residential addresses were principally in surrounding areas of the state of Selangor (48.8\%), while only $4.4 \%$ were from other states.

When the vaccination coverage was recalculated using the estimated registered live births of residents in 2005 and 2006 as the denominator, the coverage was found to be $39.4 \%$ and $85.1 \%$, respectively.

Table 3. Character of vaccination facility and availability of corresponding documentation in the Federal Territory of Kuala Lumpur, Malaysia, 2007

\begin{tabular}{lccrrr}
\hline & $\begin{array}{c}\text { Completed } \\
\text { vaccination (\%) }\end{array}$ & \multicolumn{2}{c}{$\begin{array}{c}\text { Partial } \\
\text { vaccination (\%) }\end{array}$} & Total \\
\hline Type of hospital and/or clinic & & & & & \\
$\quad$ Government & 1326 & $(98.8)$ & 16 & $(1.2)$ & 1342 \\
$\quad$ Private & 357 & $(98.6)$ & 5 & $(1.4)$ & 362 \\
Total & 1683 & $(\mathbf{9 8 . 8 )}$ & $\mathbf{2 1}$ & $(\mathbf{1 . 2 )}$ & $\mathbf{1 7 0 4}$ \\
\hline Vaccination records & & & & & \\
$\quad$ Present & 1635 & $(98.9)$ & 19 & $(1.1)$ & 1654 \\
$\quad$ Absent & 48 & $(96.0)$ & 2 & $(4.0)$ & 50 \\
Total & 1683 & $(\mathbf{9 8 . 8 )}$ & $\mathbf{2 1}$ & $\mathbf{( 1 . 2 )}$ & 1704 \\
\hline
\end{tabular}


Table 4. Estimated values for live births effect on calculated vaccination coverage

\begin{tabular}{lcc}
\hline \multicolumn{1}{c}{ Year } & 2005 & 2006 \\
\hline Children vaccinated $^{\prime}$ & 8058 & 17381 \\
Registered live births* $^{*}$ & $27500^{*}$ & $28400^{*}$ \\
Estimated live births $^{\dagger}$ & $20470^{\dagger}$ & $20431^{\dagger}$ \\
Vaccination coverage (\%), estimated & 29.3 & 61.2 \\
Vaccination coverage (\%), actual & 39.4 & 85.1 \\
\hline
\end{tabular}

* provided by the National Statistics Department

† determined by registered live births of FTKL residents

\section{DISCUSSION}

Poliomyelitis is a highly infectious viral disease that is contracted mainly in childhood and can lead to severe nerve damage, paralysis, and death via a pulmonary component. Fortunately, immunization by administration of inactivated or attenuated poliovirus successfully protects individuals and interrupts the transmission cycle. Global immunization efforts have led to near complete eradication of poliomyelitis incidence; however, sporadic outbreaks of polio virus still occur and regions exist in which the polio vaccination coverage is not $100 \%$. The large metropolitan city of Kuala Lumpur in the Malaysian state of Federal Territory of Kuala Lumpur represents one of these regions.

The Kuala Lumpur Department of Health has focused efforts on bringing the polio vaccination coverage to $100 \%$ by providing free vaccines in government clinics. To achieve this goal, however, it is first necessary to determine the current rates of vaccination, identify the target population that needs help in obtaining the vaccine, and define the factors that underlie nonvaccination. To obtain a more precise estimate of current polio vaccination coverage for children residing in the FTKL, we conducted a face-to-face survey of the residential regions throughout the city. The data collected revealed that the immunization coverage of children reached $98.3 \%$ (Cl: 97.5-99.2\%) in 2007, a number which exceeds the coverage estimated $(85 \%)$ by the State Health Department. This newly identified coverage is comparable to the estimated total polio coverage for Malaysia for the years 2006 (96.2\%) and $2007(98.7 \%)^{3}$

A similar study performed in Istanbul, Turkey garnered similar findings in that the vaccination coverage for measles determined by more precise numbers (actual from surveys as opposed to estimates from administrative records) was higher (84.5\% vs. $79.3 \%){ }^{9}$ In Malaysia, the National Statistics Department handles vital statistics based upon estimated population sizes, as was the case with live births in the FTKL region in the 2000s. While it is impossible to obtain a final definitive value of a live birth population in any region (due to such uncontrollable factors as dynamic population migration, and the inherent limitations to any random sampling procedure), it is possible to improve upon the accuracy.

By obtaining actual data from face-to-face interviews of the study population in the FTKL, we determined that the true vaccination coverage was dramatically better than that based on estimates $(98.3 \%$ in 2007 vs. $61.2 \%$ in 2006). Since approximately $25 \%$ of vaccinations were provided by private practitioners, efforts to improve private sector reporting should be continued; one of the most promising approaches is targeted education to explain the use of complete vaccination data for surveillance, evaluation and disease outbreak planning by the Ministry of Health. In addition, reporting may be enhanced by providing incentives to these practitioners, either directly or indirectly associated with monetary benefits, such as supply of free vaccines or a performance appraisal scheme. Alternatively, those clinics that provide vaccination services should be visited by the government health staff to obtain the relevant data.

According to the Istanbul study, incomplete or non-vaccination was principally due to parent's lack of knowledge about the benefits of vaccination. ${ }^{9}$ In contrast, the parents surveyed in the FTKL cited distance and lack of time as the most common reasons for non-compliance. Therefore, the main strategy for promoting compliance in the FTKL population should include making vaccination facilities more accessible (both in location and days/hours of operation). The FTKL region is a highly urbanized setting, with difficult 
road traffic conditions and a poor public transportation system. Establishing a governmental programme to deliver immunization services to residences may prove an effective means of enhancing vaccination coverage.

It is important to note here that limitations exist in our study design that may affect the generalizability of our findings. First, there is a design effect of $1.5-2$ of using a random sample size calculation for a random cluster survey which may reduce the precision of our coverage estimate. Second, live births to FTKL resident parents that occurred in other states were not accounted for; however, this number was expected to be low since most of the medical facilities are concentrated in Kuala Lumpur. Third, we did not consider the possibility that some FTKL residents may have obtained their child's vaccination from neighbouring states, and vice versa; if this number was significant it would have influenced the value determined for vaccination coverage in that particular time period. Fourth, live births of non-citizen parents are not registered with the National Registration Department, causing the official estimates of live births for the region to be lower and thereby potentially overinflating the calculated coverage; however, these individuals also represented $5 \%$ of those vaccinated. Finally, as with any study, an absolute sampling of the target population is impossible, and an unknown critical subset of the population may have been missed.

Historically, the value of estimated live births based on estimated population has been used as the denominator in the calculation of vaccination coverage. We suggest that this practice should be revised to use actual numbers of live births from the National Registration Department. To identify those parents who do not obtain the first dose of vaccination, closer monitoring of all babies born in the FTKL should be carried out. This can be achieved by interdepartmental information sharing, such as with the National Registration Department and Ministry of Health. Likewise, the default tracing process for those who have not completed their immunization should be intensified (and extended to private facilities) to attain better rates of compliance. Special attention should also be given to foreigners as they are the most likely to be unaware of services available at government health facilities.
Ultimately, this study found that although the State Health Department reported a low coverage for polio vaccination, the actual rate of children vaccinated in the FTKL reached $98 \%$. If this high rate of vaccine coverage is maintained, and possibly improved upon by more effective methods of surveillance, we might be able to attain eradication of poliomyelitis, as has already been achieved with smallpox (endorsed by the World Health Assembly in 1980). ${ }^{10}$

\section{Conflicts of interest}

None declared.

\section{Funding}

This project was funded by the National Institutes of Health under the Ministry of Health, Malaysia (National Project code: NMRR-07-451-684).

\section{References:}

1. Poliomyelitis: Key facts. Geneva, World Health Organization, 2010 (http://www.who.int/mediacentre/factsheets/fs114/en/index. $\mathrm{html}$, accessed on 26 April 2011).

2. Immunization coverage. Geneva, World health Organization, 2011 (http://www.who.int/immunization_monitoring/routine/ immunization coverage/en/index4.html, accessed on 26 April $201 \overline{1})$.

3. Health Department. The Annual Report 2005 \& 2006. Malaysia, Federal Territory of Kuala Lumpur, 2006 and 2007.

4. Laporan Kiraan Permulaan 2010. Malaysia, Jabatan Perangkaan, 2010, iv \& 27 (http://www.statistics.gov.my/portal/download Population/files/BPD/Laporan_Kiraan_Permulaan2010.pdf, accessed on 1 June 2011).

5. The Annual Report 2005, 2006 \& 2007. Kuala Lumpur: Ministry of Health: The Disease Control Division, 2005, 2006 \& 2007.

6. Naing L, Winn T, Rusli BN. Practical issues in calculating the sample size for prevalence studies. Archives of Orofacial Sciences, 2006, 1:9-14 (http://www.dental.usm.my/aos/, accessed on 18 May 2011).

7. The Director, Demography Statistics Department, The National Registration, Department, Putrajaya, Malaysia (official communications).

8. Population and Demographic Statistics Division, Department of Statistics Malaysia, Prime Minister's Department, Putrajaya,Malaysia.

9. Torun SD, Bakirci N. Vaccination coverage and reasons for nonvaccination in a district of Istanbul. BMC Public Health, 2006, 6:125. doi:10.1186/1471-2458-6-125 pmid:16677375

10. Smallpox: WHO Fact Sheet. Geneva, World Health Organization, 2001 (http://www.who.int/mediacentre/factsheets/smallpox/en/, accessed on 26 April 2011). 